EPOS, XIII (1997), pags. 151-170

\title{
OBSERVACIONES FLLOLÓGICAS SOBRE ASPECTOS RELATIVOS AL MEDIO AMBIENTE EN LA DOCUMENTACIÓN NOTARIAL ${ }^{1}$
}

\author{
Pilar DifZ de Revenga Torres \\ Universidad de Murcia
}

\section{RESUMEN}

En el presente artículo analizamos desde una perspectiva filológica el tratamiento que se ha dado en la documentación notarial de diversos lugares de España durante los siglos XIII, XIV y XV a los problemas medioambientales que, en apariencia, son únicamente una preocupación actual.

Si comparamos esos documentos notariales medievales, articulados sobre la base de lexías complejas, en los que se pueden apreciar los rasgos linguísticos propios de los escribanos, con los artículos que aparece en la prensa actual, veremos que los problemas y contenidos son muy semejantes.

La riqueza de la documentación notarial de distintos puntos de España y la abundancia de alusiones a la conservación del medio ambiente, así como el

' Un esbozo del presente artículo fue lefdo como conferencia, con el túlo La documentación notarial, importante fuente de datos sobre problemas medioambientales en el ciclo El tratamiento del medio ambiente en los textos juridicos; Universidad de Valladolid, diciembre de 1996. 
espacio de que disponemos, nos ha llevado a limitarnos al tratamiento que recibe el agua en estos textos de los siglos XIII, XIV y XV, con algún ejemplo aislado de siglos posteriores ${ }^{2}$.

Tanto en la conservación del medio ambiente como en su deterioro podemos detectar la presencia del hombre que lo protegerá o lo sobreexplotará has-

2 Seguidamente presentamos la relación de colecciones documentales utilizadas. Los ejemplos son muy numerosos y similares; por ello, hemos renunciado a incluirlos todos en este trabajo. Nos limitamos, por lo tanto, a seleccionar los más significativos. A.C.M.: Archivo de la Catedral de Murcia. A.M.M.: Archivo Municipal de Murcia. Ávila: Monsalvo Antón, J.M. (ed.): Ordenanzas de Ávila y su tierra. Fuentes históricas abulenses, 5. Ávila, 1990. Génesis. Bover, J.M y CANTERA, F. (trads): Sagrada Biblia. B.A.C.; Madrid, 1961, 6" ed. Cat. León: SAEZ, E. (ed.): Colección documental de la Catedral de León (775-1230); I: 775-952. Centro de Estudios e Investigación «San Isidoro». León, 1987. CL: SER QUIJANO, G. del (ed.): Documentación de la Catedral de Leon. Univ. de Salamanca, 1981. CODOM II: TORRES FonTES, J. (ed.): Colección de documentos para la historia del Reino de Murcia, II. Documentos del siglo XIII. Murcia, 1969, CODOM XIII: GARCIA DIAZ, I. (ed.): Colección de documentos para la historia del Reino de Murcia, XIII. Documentos del siglo XIV-4. Archivo de la Catedral de Murcia. Murcia, 1989. FJuzgo: Real Academia Española: edición del Fuero Juzgo en latín y castellano. Madrid, 1815. Fuero Real: Alfonso el Sabio. Ed. de Azucena Palacios. Barcelona. Ed. PPU, 1991. HRey: Palacín, M.C. y MARTf́nez, L.(eds.): Documentación del Hospital del Rey de Burgos (1136-1273). Burgos, 1990. Huelgas: Castro, A. y Lizoafin, J.M. (eds.): Documentación del Monasterio de las Huelgas de Burgos (1284-1306). Burgos, 1987. León I: MARTín López, M E. (ed.): Patrimonio cultural de San Isidoro de León. I: Documentos de los siglos X-XIII. Universidad de León, 1995. Mirav.: GarGaLlo MoYA, A.: (ed.): «Documentos del Archivo Municipal de Miravete de la Sierra. Teruel (1279-1499)» en Teruel, $\mathrm{n}^{\circ}$ 68. Teruel, 1982; págs. 47-124. Mont.T: GARCía ARAGÓN, L. (ed.) Documentación del Monasterio de la Trinidad de Burgos (1198-1400). Burgos, 1985. Murcia: Ordenanzas y costumbres de la huerta de Murcia. Edición y estudio preliminar de J. CERDÁ RUIZ-FunEs. Murcia, 1969. PCG: Menéndez Pidal, R.,G. Solalinde, A., Muñoz Cortés, M. y Gómez Pérez, J. (eds.): Primera Crónica General de España. Ed. Gredos; Madrid, 1955. Piedrahíta: Luis LoPEZ, C. (ed.): Colección documental del Archivo Municipal de Piedrahita (1372-1549). Fuentes historicas abulenses, 3. Ávila, 1987. Rioja: RodRIGUEZ R. DE LAMA, I. (ed.): Colección diplomática medieval de la Rioja. T. IV: documentos del siglo XIII. Instituto de Estudios Riojanos. Logroño, 1989. Sahagún, III: HerRero DE la FUenTE, M. (ed.): Colección diplomática del Monasterio de Sahagún (8571230). III: 1073-1109. Centro de Estudios e Investigación «San Isidoro». León, 1989. Sahagún V: FernándeZ Flórez, J.A. (ed.): Colección diplomática del Monasterio de Sahagún (857-1300). V: 1200-1300. Centro de Estudios e Investigación «San Isidoro». León, 1994. Sahagún IX: MiNGUEZ FERNÁNDEZ, J.M. (ed.): Colección diplomática del Monasterio de Sahagún (siglos IX y X). Centro de Estudios e Investigación «San Isidoro». León, 1976. SBenito: Sobrino CHOMÓ, T. (ed.): Documentación medieval del Cabildo de San Benito de Ávila. Fuentes históricas abulenses, 7. Ávila, 1991. SJBurgos: PEÑA, F.J. (ed.): Documentación del Monasterio de San Juan de Burgos (10911400). Burgos, 1983. SSOña: Oleja Gonzalo, I. (ed.): Documentación del Monasterio de San Salvador de Oña (1285-1310). Burgos, 1986. SZoilo: Pérez CeladA, J.A. (ed.): Documentación del Monasterio de San Zoilo de Carrión (1043-1300). Palencia, 1986. TNT: NAVARro ToMÁs, T. (ed.): Documentos lingüísticos del Alto Aragón. Syracuse University Press. New York, 1957. Valvanera: Garcfa Turza, F.J. (ed.): Documentación medieval del Monasterio de Valvanera (siglos XI al XIII). Zaragoza, 1985. 
ta su destrucción; lo que ahora nos parece un hecho moderno y de actualidad no es más que una preocupación que se ha sentido a lo largo de la historia. Desde los orígenes se legisla sobre el agua, la tala de árboles, protección de animales y de ello tenemos abundantes ejemplos en cualquier fuero.

El agua es premio y castigo; en el Génesis, en el pasaje de la creación, ya se habla de ella cuando Dios la separa de la tierra y así se presenta también en el Corán ${ }^{3}$ :

Dijo Dios luego: «Reunanse las aguas de debajo de los cielos en un lugar y aparezca lo seco». Y así fue. Y Dios llamó a lo seco tierra y a la reunión de las aguas llamó mares. Y vio Dios que estaba bien (Génesis).

Los documentos medievales - como decíamos antes- son preciosa fuente de información de otros tiempos y nos ofrecen una copiosa colección de ejemplos que expresan la preocupación por este bien tan escaso en algunas zonas y tan abundante otras veces, que causa desastres; de nuevo en el Génesis se narra el castigo divino:

Pues he aquí que yo voy a atraer el diluvio de aguas sobre la tierra para destruir todo ser corpóreo en que alienta espíritu de vida debajo del cielo. Todo cuanto existe en la tierra expirará

Del diluvio no sólo se trata en la Biblia; en un documento en el que se dispone cómo han de jurar los judíos sobre la tora y en nombre de Dios se da un repaso a las Sagradas Escrituras, a los premios, castigos y milagros de Dios; se recuerda, incluso, a los oscuros personajes bíblicos Datán y Abirón, tan presentes en las maldiciones medievales que, articuladas sobre la base de lexías complejas, terminan desapareciendo por causas extralingüísticas ${ }^{4}$; veamos únicamente las alusiones al agua que en este texto se presenta primero como castigo y después como premio:

Et por aquel Dios que rescibio el sacrificio de Abel e desecho el de Cain e saluo a Noe en el archa en el tiempo del diluuio... e goardo a Moysen seyendo ninno qoando lo echaron al rio ... e dio de comer en el desierto manna e fizo salir de la piedra seca agua dulce para que

3 VIDAL CASTRO, F: «El agua en el derecho islámico. Introducción a sus origenes, propiedad y uso" en El agua en la agricultura de Al-Andalus. Lunwerg eds. et al.; págs.99-117.

4 Diez De ReVEnga, P.: «Algunas expresiones de la sanctio en cartas medievales» en Voces, $2,1991$. 
beuiessen ... e Josue a qui fizo que passasen del rio Iordan por seco tornando las aguas arriba ... (Rioja, 432)

Una tempestad, o una guerra, puede hacer que se supriman o se modifiquen los pagos estipulados:

Todo esto damos a vos don Pero Sanç devandito que lo tengades en vostros dias dando vos ... cada aino vint kafiçes de trigo ... maguera si por huest o por tempestad de piedra menoscabaren los fruitos del heredamiento ... que el menoscabo que averra en el trebudo d'aqueil aino sea contado. (Rioja, 421)

En la Primera Crónica General también se narran hiperbólicamente épocas de gran sequía a las que siguen abundantes lluvias:

...e mouieron allí un grand tiempo fasta que vino la gran seca que duró XXVI annos que no llouio en Espanna, porque ouieron a foyr todas las yentes de la tierra, e murieron aquellos dos ermanos. $E$ no finco rio en toda Espanna ques no secasse sino Guadalquiuir y Ebro, y estos corrien muy poco... e despues uinieron tres annos que nunqua fizo al sino llouer, de guisa que toda la tierra era cubierta dagua que semeiaua mar (PGC)

Hemos visto hasta ahora que el agua, este bien tan preciado y tan indispensable, puede causar grandes daños. En la documentación medieval se manifiesta con mucha frecuencia el temor a que el agua, entre otras causas, haga desaparecer un texto, lo que ocasiona que se copie una o más veces, años o siglos después. Es una de las razones, no la única, por las que hubo una abundante transmisión documental, originando las copias que tantos problemas nos presentan a los filólogos y que alcanzan a textos literarios por otras causas. ${ }^{5}$

Este temor se expresaba por medio de la lexía compleja, «por agua o por fuego o por robo», que aparece en muchos documentos; más tarde a estos temores se les suma la acción corrosiva de los ratones:

5 ARIZA Viguera, M.: «Diferencias textuales en los manuscritos del Libro de los Buenos Proverbiosw en Anuario de Estudios Filológicos, V; 1982; págs. 7-16. Dízz DE Revenga TORRes, P.: «La Historia de la doncella Teodor: variaciones sobre un mismo tema» en La variation linguistique et textuelle. Théorie, Moyen Age hispanique en l'honneur de Jean Roudil. París, en prensa y «Texto y variantes: a propósito de la Segunda Partida» en Glossae, 3, 1992; págs. 165-198. Diez De Revenga, P. y Garcla Diaz, I.: «Problemas linguísticos en los copistas medievales I y II en Anales de Filología Hispánica. Univ. de Murcia. I: 2, 1986; págs. 9-25 y II: 4, 1988-89; págs. 59-73 y «Manuscritos y copistas: los Usatici Barcinonae; Glossae, 7; en prensa. 
Et el dicho don Iohan, prior e camarero, dixo que esta dicha carta que la auia de enbiar a casa de nuestro sennor el rey a confirmar ... e que la non osaua auenturar por los caminos, que eran peligrosos, por miedo que se podía perder por agua o por fuego o por robo ... (S. Zoilo, 201).

y $\int_{i}$ faltan algunas cartas de Reyes de/las que pare $\int c e n$ por otros memoriales na/die $\int_{e}$ marauille que como heran en papel ra/tones y el tiempo las confumieron (A.C.M., Libro, 211, 1536) ${ }^{6}$.

El agua caliente también se utiliza como arma ofensiva lanzada desde las almenas o como prueba de la resistencia en determinados procesos; esta prueba se ha conocido como ordalía y es semejante a la del hierro caliente. Con la mano envuelta en un paño de lino, el acusado debe coger unos cantos o piedras que se han depositado en un recipiente con agua hirviendo; en principio, un sacerdote bendecía las piedras, pero tras el Concilio de Letrán esta bendición se sustituye por la del alcalde, un merino o uno de los fieles ${ }^{7}$

E non aya fuero para fazer batalla nin de fierro ni de aqua calient, si non podiere firmar con dos vecinos daquella villa e peche su calonia qual juzgada fuere (Rioja, 69)

Si en principio pudimos pensar que había una gran diferencia en los documentos del norte peninsular, que representarian la España húmeda, frente a los del sur, la España seca, estaríamos equivocados. Aunque la proporción no es idéntica, pues en el sur es mayor, en los documentos norteños también es un tema frecuente.

De una manera más o menos directa el agua está relacionada siempre con el hombre, que la utiliza primordialmente para satisfacer sus necesidades básicas. Respecto al consumo humano debía haber un abastecimiento regular, a veces, se explica que se arrienda una casa con su correspondiente pozo o que se produce una disputa por la rotura de la medianería de un pozo:

... e que ha dos casas tejadas ... e con su corral e con su pozo ... (SBenito, 39 y 40 ).

... el qual dixo que aquel poço era por meytat, e que auia enaquel $\mathrm{ju}$ part ... e quent podia prender e trayer e e los fuyos agua del dito poço... (TNT, 69)

- Queremos dar las gracias a la Dra. Isabel García Díaz por proporcionamos generosamente este dato.

${ }^{7}$ Lalinde Abadia, J.: Iniciación histórica al derecho español. Ariel; Barcelona, 1970; págs. 792-793. 
En Ávila se estipulan las medidas que han de utilizar los aguadores, de la misma manera que se legisla qué aguas sirven para regar o para pescar:

Hordenamos e mandamos que los aguaderos desta dicha çibdad e sus arravales, o que de fuera parte vienen a vender agua en ella, trayan los cantaros que faga cada uno seys açunbres... (Ávila, Hordenança de los aguaderos).

Es frecuente, lo veremos más adelante, que se haga referencia a los abrevaderos para el ganado; no lo es tanto que se trate de la bebida para el hombre. En el siguiente texto encontramos un ejemplo:

... de como el Cabildo y la iglesia de Sant Andres de Armentia son en posesion e tenençia derecha de los quartos de la vua e de la maçana e de todo el beuer de todo el Arcidianagdo de Alaua... (Rioja, 280).

En otro documento riojano se confiesa haber recibido en arrendamiento el Hospital de la Cadena con todas sus heredades, algunos animales (cuatro bueyes y dos asnos), los aperos de labranza y el menaje de cocina durante ocho años. Con documentos de este tipo podríamos reconstruir parte de la vida cotidiana si supiéramos exactamente qué es el agua uino aunque sospechamos que se trata, simplemente, de vino aguado:

...tres coquas de uino, las dos de mosto e la tercera de agua uino, e cinquo coquas de uino para despensa un tocino ... (Rioja, 313).

En los textos medievales aparecen apodos o sobrenombres ya que son tan antiguos como la historia de nuestra lengua: Los apodos, dentro del sistema onomástico, tienen un mayor margen de libertad e inventiva que el nombre o el apellido, sobre los que no tenemos control o, si lo tenemos, es limitado; además es más trasparente lingüísticamente, es cómodo, hace sonreir y se entien$\mathrm{de}^{8}$. En muchas regiones españolas son tan antiguos como la documentación romance que conocemos. Torres Fontes considera que «no era un capricho ni un hecho ocasional, sino todo lo contrario, una exigencia para satisfacer una necesidad: la de distinguir y singularizar» en las largas relaciones nominales de los libros de Repartimiento. Dado el cuantioso número de pobladores y el que muchos de ellos procedieran de una misma localidad y tuvieran igual nombre

8 CARDONA, G.R.: «Il nome proprio come marca di differenziazione» en Sociolinguistica. Loescher editore. Torino, 1987; págs. 79-87 
hacía necesario distinguir y diferenciar para poder conocer a cada uno de ellos. Y con frecuencia el sobrenombre pasa a convertirse en apellido de manera formal y hereditaria: Rojo, Mercader, Calvo, Cano, etc. ${ }^{9}$

No sabemos realmente si el que aparece en una carta de arrendamiento de Calahorra está relacionado con el agua o sólo lo aparenta. No hay datos que nos indiquen si se trataba de un paniaguado (lat. panificare > paniguar > paniaguar; eran aquellos a quienes un señor daba pan o alimentaba y, en este caso, la voz acqua no interviene en principio en la etimología ${ }^{10}$. Paniagua es otro ejemplo de cómo un apodo se convierte en apellido). Igualmente se podría referir a una persona muy austera:

... arrendamos nuestra casa en barrio de Sant Andres, la que fue de don Rodrigo, «pan y agua» que ha allactaneos... (Rioja, 379)

Además de por otras fuentes ${ }^{11}$, en Murcia se conoce la existencia de baños por un documento de arrendamiento en el que se explica el estado en que se encuentran:

En los quales bannos esta agora vna caldera grande nueua con que se callenta el agua para los dichos bannos e los dichos bannos estan los suelos losados de sola de piedra de marmol, e esta vna casa buena nueua con sus puertas nueuas e çerraduras para en que mora el que tiene los bannos (CODOM, XIII, 83)

El agua sirve, asimismo, para marcar fronteras entre propiedades y en este aspecto hay una gran diferencia entre el norte y el sur en virtud de los sistemas de regadío ${ }^{12}$; en Murcia, el sistema es de origen árabe. Por iniciativa del Concejo de la Ciudad se repartían las aguas entre los propietarios y ésto dio lugar a una serie de costumbres que perduraron tras la reconquista cristiana. Decía Joaquín Costa:

Regad los campos si quereis dejar rastro de vuestro paso por el poder; los árabes pasaron por España: ha desaparecido su raza, su religión,

9 TORRes Fontes, J.: «Apodos y sobrenombres en el Repartimiento de Murcia» en Monteagvdo, 55, 1976; págs. 9-12. DIEZ DE REVENGA, P.: «Motes y apodos en la prensa murciana» en BRAEX, IV, 1993; Págs. 65-75.

10 DRAE, s.v. paniaguado; Corominas, J. y PASCuAl, J.A.. DCEEH, s.v. pan.

$"$ TORRES Fontes, J.: «Los baños de la reina» en Murgetana, 40, 1975;págs. 69-73.

12 CERDA Ruiz-FunES, J.: Edición y estudio de las Ordenanzas y costumbres de la huerta de Murcia. Junta de Hacendados; Murcia, 1969, págs. 5 y ss. VIDAL CASTRO, F.: «El agua en el derecho islámico. Introducción a sus origenes, propiedad y uso». op. cit., págs. 99-117. 
sus códigos ... Sin embargo, su memoria está viva porque han subsistido sus riegos ${ }^{13}$

Alfonso X el Sabio otorg6 privilegios que fueron confirmados por otros monarcas castellanos de la Baja Edad Media y de la Moderna. La actividad del Concejo de la Ciudad se recogí a lo largo del siglo XIV en el Libro del Agua o primeras ordenanzas de la huerta de Murcia.

Si las prácticas y usos de los musulmanes fueron continuados por los cristianos es como un legado árabe que se refleja, incluso, en la toponimia. García Soriano dice:

Basta con ir recordando los nombres de muchos pueblos y partidos rurales de aquel reino [se refiere al de Murcia]: Abarán, Albatalía, Azacaya, Beniaján, Ceutí, Javalí, Ricote, etc., palabras todas tan moriscas y tan murcianas a la vez; así como los nombres de muchas de las acequias que riegan las Huertas de Murcia y Orihuela: Albadel ..., Aljucer..., Aljuffa..., Alquibla, Belchí, Benicomai, ...Rahal, etc» ${ }^{14}$.

García Soriano, no obstante, considera que castellanos y aragoneses sustituyeron muchos toponimos árabes por otros de sus propias lenguas porque les resultaban incomprensibles y de difícil pronunciación.

En el capítulo sexto de las Ordenanzas de la Huerta ${ }^{15}$ se explica el funcionamiento de un doble sistema: 1) cauces de aguas vivas o de regadío y 2) cauces de aguas muertas o cauces que sirven para descargar la excesiva humedad de la tierra. Se organizan grandes conflictos, si por alguna razón, al regar una tierra pasa agua a otra ya regada, lo que se conoce en castellano como sorriego y en murciano como sonriego; En el siguiente escrito hemos respetado la ortografía; únicamente hemos separado algunas palabras y unido otras para facilitar la lectura. Observamos algunos rasgos propios del murciano como el trueque de alveolares o la epentesis de $n$ en muncho, comunes uno a las hablas meridionales y otro al español vulgar ${ }^{16}$. Es curioso comprobar cómo una persona que escribía con cierta dificultad y dejaba entrever rasgos propios de

${ }^{13}$ Costa, J.: Polftica Hidráulica; Madrid, 1911, pág. 1. Apud J. CERDA: Edición y estudio de Las Ordenanzas de la Huerta de Murcia, op. cit.

14 GaRcía SoRIano, J..Vocabulario del dialecto murciano. Murcia, 1932; reimpresión en 1980. Pags. XXXVIII y ss.

15 op. cit., págs. 53 y ss.

16 MuÑoz CoRTés, M.: El español vulgar. Biblioteca de la Revista de Educación; Madrid, 1958. MUNOZZ GarRigós, J.: «En tomo a $-\mathrm{r}$ y -1 implosivas en la provincia de Murcia (reflexiones sobre el A.L.P.I.) en Miscel.lania Sanchis Guarner, II. Quaderns de Filologia. Universitat de Valencia, 1984; págs. 225-228. 
su idiolecto conocía perfectamente las fórmulas precisas para dirigirse al alcalde de la ciudad.

Doy parte al Sr. Alcalde de esta capital como en el camino de Santa Catalina ha habido un sonriego de unos setenta metros siendo la causa el puente de la azequia (sic) de la *Enquibla madre por estal el puente mas vajo (sic) que el camino y con poco intervalo que tenga salta el hagua (sic) por lo halto (sic). Lo pongo en conocimiento de V.S. para que haga lo que tenga por conveniente. Guarde Dios a V.S. munchos años. El cavo (sic). (A.M.M., legajo 320, 1886).

Se explica también y lo citamos como cosa curiosa, cómo se han corrompido los nombres árabes en su transmisión a lo largo de los siglos ${ }^{17}$ :

Error grande sería el de quien, al reconstruir la historia de nuestra huerta, tomase por guía principal los nombres de los cauces ... muchos de aquellos subsisten aunque desfigurados, otros tradujeron los conquistadores y alguno que parece traducido, fue ya usado por los moros...

Da tres ejemplos de clara etimología popular: 1) la acequia de la Herrera que los moros y primeros cristianos llamaron Al Ferraira. 2) El nombre de un partidor, Dardalla, se convirtió en Ardalla; a partir de ahí, un arabista encuentra la etimología «ard allah» (tierra de Dios) y de ahí deduce que ese partidor regaba tierras de una mezquita. 3) El escorredor Barraumal (vertedero de aguas) se conserva con pocas alteraciones y hoy se conoce, sin saber por qué, como Barriomar.

En la España húmeda, cuando se marcan los límites mediante el agua se hace por medio de cauces naturales con escasa manipulación humana. Los rios, las gargantas y los arroyos están presentes así como los azudes y son éstos últimos los que necesitarían de una explicación; procedente el término del árabe sudd significa «presa para tomar agua de los ríos» 0 «rueda hidráulica que sirve para el mismo efecto»:

... e de la otra parth, casas e orto de don Iuan Aluaro, e detras, el arroyo... (SJ Burgos, 70).

La utilización de los ríos y de los azudes como límite de una propiedad se utiliza indistintamente en el norte y en el sur:

17 Ordenanzas... Op. cit., pág. 55. 
...que affruenta con campo de los fillos de Domingo Gallen, con carrera publica et con el rio (Mirav., 23)

...et de la mano derecha al donadio fasta el rio de Segura (CODOM, XIII, 38)

Primeramente, allende el rio la torre de don Manuel... (CODOM, XIII,38)

...que affruenta con campo de Juhan Ferando ... e con el rio (Mirav., 24)

Et que destas seys o siete tafullas que estan en cabo del dicho barranco fasta el rio a fita cubierta et dende arriba commo dize el rio fasta el Açud (CODOM, XIII, 38)

En los documentos del sur, concretamente en los de Murcia, los límites se marcan también con los azarbes. Del árabe (as)sarb, es un cauce a donde van a parar por las acequias -o cauces más pequeños- las aguas sobrantes o las filtraciones de los riegos:

Item, que ha el granero del donado en el almarjal del camino de Orihuela, commo dize el camino de Pero ... Salle al açarbe que pasa yuso las Casiellas e la çequia de Casiellas... CODOM, XIII, 38)

...de camino a camino, fasta el açarbe del s[al]ze que va al cabo de las vinnas ...» (CODOM, XIII, 38)

Las acequias, del árabe (as)sâqiya, son los canales por donde se conducen las aguas de regadío u otros fines. Características del regadío murciano, y levantino en general, también se encuentran ejemplos en documentos de Aragón:

Otrossi faze Belenguer Puig dotze maravedis por vnas casas que son fuera de la Puerta Nueva de Murcia, a tiniente de la çequia mayor (CODOM, XIII, 18)

...parte una senda ençima de los Teiares et va a la çequia de Churra derecha (CODOM, XIII, 38)

... que son en el casar que dizen de Berenguer Balle, en la çequia de Aljuffia, huerta de Murcia ... (CODOM, XIII, 76)

e en lecunda part, en çequia vecinal (TNT, 19) 
...que afruenta a la dicta heredat de la una part, e con çequia vecinal de la otra con poto ...(TNT, 50)

Las ramblas, del árabe rámla, o lecho natural de las aguas cuando caen copiosamente, delimitan asimismo una propiedad como lo hacen, incluso, los desagües:

...que trauiessa la rambla de la Buxnegra e va al camino ques de la Adaua viejo ... (CODOM, XIII, 38).

... que afruenta con tierra de vos dichos compradores et con exagüadero de la hagua de la dicha vega ... (Mirav., 27).

Ramón Martí ${ }^{18}$ señala para Cataluña que los señores jurisdiccionales eran dueños de las aguas que existían en sus dominios, propiedad que se definía con el término aquis aquarum. Comprueba que en las actas de ventas de molinos entre particulares durante el siglo $\mathrm{X}$ nunca figura el agua entre las propiedades vendidas. Por el contrario en los documentos murcianos el agua, ya sean ríos, fuentes, molinos o aceñas (del árabe as saniya, es una rueda hidráulica que eleva el agua), se vende o se arrienda junto con la tierra porque uno de los principios tradicionales en los regadíos españoles es que la propiedad de la tierra de regadío lleva consigo el uso y disfrute del agua en días y horas señalados. Las distintas transacciones de las propiedades incluían todo: montes, pastos, ganados e, incluso, personas. Así, podemos ver un caso de donación recíproca de 1243:

...damos e otorgamos a uos don Gil Gomeç el nuestro castillo que es llamado de Paracollos, con la villa e con sus terminos, con entradas e con salidas, et con aldeas pobradas e por pobrar,e con uinnas e con ortos et con moros e con ganados e con rios e con fontes e con pascos e con montes e con açenias e con molinos ... (CODOM, II, 2, 1243).

En tal manera que los ayades quitos e liures por heredat uuestra e por iuro de heredamiento con entradas e con exidas, con aguas e con ryos e con todas sus pertenencias, del çielo fasta en los abismos, por vender e por enpennar e por fazer dellos a toda uuestra uoluntat en uida e en fin (Rioja, 295)

18 BARCELO, M. el al.: Arqueología medieval. En las afueras del medievalismo. Ed. Crítica; Barcelona, 1988; págs. 175 y ss. 
...todo lo que auyan en Aynar, los palacios e todos los heredamientos, granados e menudos del çyelo ata la tierra, de las agoas ata las yerbas ... (Rioja, 428).

...offero, dono et concedo Deo et monasterio Sancti Facundi et uobis dompno Petro, eiusdem loci abbati, et universo conuentui ut aqua que discurrit de riuo de Ceya ... (Sahagún V, 1535)

Zimmermann ${ }^{19}$ analiza un número considerable de documentos catalanes de los siglos X al XII y encuentra en su estructura largas enumeraciones, a menudo estereotipadas y repetitivas pero que afectan a diversos objetos y aspectos de la vida. Halla en estas enumeraciones cinco categorías diferentes. Nos interesa especialmente la última que se refiere a los detalles del bien que el donante o arrendador cederá. Aunque considera que es la más banal, opina que está estrechamente ligada a la transmisión de un derecho de posesión o de uso de un objeto. Es frecuente en las donaciones, cambios o ventas, pero no aparece en los testamentos porque muestran una estructura jurídica y diplomática diferente. Las formulas empleadas son diversas; el orden del inventario, la disposición de sus elementos o las relaciones gramaticales son muy variadas.

En estas enumeraciones, la estructura manifiesta la voluntad de hacer una descripción exhaustiva; las características del bien objeto de la transacción deben ser especificadas y detalladas. Incluso, y con frecuencia, se introduce la lexía compleja «omnia et in omnibus» o «cum omnibus suis pertinentiis» en los documentos latinos y «con todas sus pertenencias» en los romances para paliar el riesgo de olvido.

Señala Zimmermann que este tipo de enumeraciones no queda abandonada al azar sino que es fruto de una construcción rigurosa:

1) Se encuentran formulas que asocian términos de valor contrario: «con entradas y con salidas».

2) Se agrupan ciertas palabras semejantes en dípticos o trípticos, siguiendo las leyes de la sinonimia o de la analogía: «e con ríos e con fontes», «e con açenias e con molinos», «e con pascos e con montes». En este aspecto, habría que analizar si forman un díptico «con moros e con ganado» (vid. el ejemplo de CODOM, II, 2, 1243 citado más arriba) o si simplemente se encuentran juntos por pura coincidencia. Se podría pensar que es una casualidad si «con moros e

19 ZIMMERMANN, M.: «Glose, tautologie ou inventaire? L'énumération descriptive dans la documentation catalane du Xeme au XIIeme siecle» en Cahiers de Linguistique Hispanique Médiévale, 14-15; 1989-1990; págs. 308-338. 
con ganados» estuviera en posición final de la enumeración, pero vemos que se encuentra intercalado entre otros pares; pudo deberse al azar, a la poca atención del escribano o a su mentalidad. Quizá habría que documentar este díptico -en el caso de que lo fuera- antes de extraer conclusiones aunque lamentablemente no sería el único caso de racismo en un texto escrito ${ }^{20}$.

3) La adjetivación repartida oportunamente permite la apertura de espacios o dominios nuevos: «aldeas pobradas e por pobrar».

4) El uso generalizado de la preposición «cum» (o «con») que invita a explorar los elementos implícitos en el concepto inicial. Los ejemplos son abundantes, tanto en latín como en romance, aunque en latín puede no aparecer «cum» (cfr. infra):

... de omnem meam ereditatem quidquid uisa sum abere in uilla quod uocidant T.: terras, uineas, pomares, ceresiares uel omnia fructuaria, montibus, fontibus, exitos, cessum et regresum ubique de mea ereditate... (CL, 950).

...quem abemus in locum predictum in Porma, ad Ofilones: corte, terra, pumares, ortales, pratus, sotos, linn[ares, c]essum uel regressum ubi potueris inuenire... (CL, 997).

Placuit nobis, propria nobis voluntate, ut faceremus uobis iam dicto Ansuri cartulam uendicionis de uno linare, cum suo prato et cum sua aqua, in uilla quam uocitant Uilla Burgala ...(Sahagún V, 753).

...qui est situm in illius parte de Okon, cum suis terris, vineis, introitis et regressis vel cum quantum ad eum pertinet ab omni integritate sit vobis concessum adque ingenuum (Valvanera, 70 ).

El carácter tipológico de la enumeración justifica el rigor casi retórico de los inventarios. Se explica el recurso de la presentación en forma de binomios o trinomios; mientras que los primeros expresan una complementaridad o la alternativa, los segundos son útiles para evocar una suma de elementos o su totalidad.

El orden de palabras o los cambios de vocabulario a lo largo de la tradición escrita no se pueden atribuir -dice Zimmermann- a la fantasía del escriba. Considera que se deben a la transformación económica de los diferentes lugares. De la cesión del agua hay abundantes ejemplos:

20 Bañón HeRnÁNDEZ, A.M.: Racismo, discurso periodístico y didáctica de la lengua. Univ. de Almeria, 1996. 
Otrossi, les otorgo que el agua con que se regauan las alcarias do son estas heredades que la ayan assi como la solien auer los moros en el so tiempo (CODOM II, 39)

...do et establesco a ençiensso ... diez taffullas de terra en regadio con su parte del agua (CODOM II, 58)

...confirmamosle las casas et todos los heredamientos et aguas que tienen ... (CODOM II, 71)

... et con todos sus terminos et con fuentes et con rios ... (CODOM II, 110).

Reconstruimos los avatares históricos a través de los documentos que nos los narran. En ellos queda huella de las preocupaciones y deseos o ambiciones de quienes gobernaban. La frontera entre Castilla y Aragón siempre fue una línea que cambiaba según las épocas. En la segunda mitad del siglo XIII la situación del reino de Murcia, que formaba parte de la Corona de Castilla, fue muy inestable; sirvi6 muchas veces como prenda para mantener la fidelidad de reyes y príncipes a los soberanos de Castilla. ${ }^{21}$ En el documento de donación que hizo D. Alfonso de la Cerda al rey de Aragon, Alfonso III, en 1289, se incluyen las aguas, tanto dulces como saladas; o sea, ríos y mares:

do e otorgo a uos dicho rey de Aragón ... el regno de Murcia ... et con los mares del dicho regno et con rios et con otras aguas dulçes et saladas (CODOM II, 96).

Las norias, del árabe na'ura, son máquinas compuestas de dos ruedas: una horizontal movida por una palanca de la que tira una caballería y otra vertical que engrana en la primera y lleva una maroma con arcaduces (o caños) para sacar agua. En Murcia, es curioso que una de estas ruedas de origen al top6nimo La Ñora y éste, a su vez, de nombre a un característico pimiento de bola, picante o no, que una vez molido es el pimentón.

Según Corominas ${ }^{22}$, noria procede de una alteración del antiguo (a)nora por influjo de acenia y acequia. (A)nora viene del árabe $\overline{n a}^{c}$ ara; desecha la idea

21 TORRES FonteS, J.: «La delimitación del sudeste peninsular (Torrellas-Elche, 13041305)». Publicaciones de la Universidad de Murcia, 1951; págs. 5-21, especialmente 8 y 9. «La delimitación del sudeste peninsular (Tratados de partición de la Reconquista)». Publicaciones de la Universidad de Murcia, 1950; págs. 5-32.

22 Corominas, J. y Pascual, J.A.: DCEEH, s.v. noria 
de García Soriano y de Steiger sobre la evolución fonética ya que proponen una metátesis *aniora $>$ anoria porque «nunca existió ni pudo existir una pronunciación *aniora; anyora es el caso de la grafía catalana ny $=\tilde{n}$ cuyos elementos no eran disociables (la ñ se debe a la nn del árabe an-nă ûra). Más bien se podría pensar en una metátesis árabe vulgar nă $\bar{a}^{c}$ ura $>$ nurấc a (dada la propensión del ain a las metátesis), de donde una acentuación vulgar nûre ${ }^{c} a>$ nória, pero ésto es demasiado hipotético. Es en cambio muy razonable la idea de Neuvomen de una contaminación por parte de acequia y acenia».

Muñoz Garrigós ${ }^{23}$, basándose en la existencia de ejemplos con palatal ñ y epéntesis de yod, del tipo annoria, cree que Steiger tenía razón. En la adaptación de apellidos catalanes a la fonética murciana se disocian las palatales del sonido ch -ortografiádo ig-: Cabo Roig y no Roch, Puigcervert y no Puchvert, etc.

...sobre la parte ... de la uinna et de la annora ... (CODOM II, 92)

...la mi parte et derecho de la dicha huerta ... et annoria con so agua et de la rambla ... (CODOM II, 92)

...los molinos del alcaçar non auian agua para çinco molas e para el anyora que suelten tanta agua de la presa de los molínos de la companya que y cumpla, empero si en este lugar non fazian nora e de suso por la açequia nueva querran fazer llauor por annora por canal porque se regasse el arraual ... (CODOM XIII, 1).

Et si esto non fazian que todauia suelten tanta agua del açut de la companya que cumpla a las çinco molas et annora como dicho es (CODOM XIII, 1).

Los molinos son maquinarias para moler impulsadas por una fuerza motriz que puede ser el agua, el viento, el vapor o cualquier otro agente mecánico. Los ejemplos que citamos a continuación están en función de su relación con el agua. Dada su cercanía con el río o las referencias que se hacen al agua pensamos que debían estar impulsados por esta fuerza motriz:

...en razón de los molinos que cada parte dellos auian o entendian auer en el rio de Segura, de que amas las partes auian priuilegios de nues-

${ }^{23}$ MuÑoz Garrigós, J.: «A propósito de 'noria' y 'ñora'» en Monteagvdo, 76, 1982; págs. 5-14. 
tro sennor el rey para fazerlos entre el alcaçar e la puente de Murcia e leuar el agua por la carcaua de la villa ... (CODOM XIII, 1).

Como veremos más adelante, no siempre se pueden evitar las disputas por el disfrute del agua como se nos narra en este texto:

Amas las partes, por escusar pleito ... auinieronse en esta manera: que los dichos molinos quantos y podiessen fazer fuessen e ouiessen entre ellos por medio, assi que el una parte aya la meatat e el otra parte la otra meatat. Et toda la mission daquellos fazer e de la presa del rio ... (CODOM XIII, 1).

Sancho IV, a la vista de una carta de su padre, el rey D. Alfonso, que le mostraban su tía, la infanta $D^{\mathbf{a}}$ Berenguela, y la abadesa del Monasterio de las Huelgas, dispone que nadie embargue las aguas que han de ir a los molinos que les correspondían, bajo pena de castigo:

[la carta] en que diçe que mando façer pesquisa en raçon de las aguas que an de auer e deuen venir a los sos molinos de la su casa de Poblaçion de Soto ... e que las an de tomar en estos logares connobrados: la presa de sobre Poçuela ... (Huelgas, 39).

La preocupación por las aguas contaminadas tampoco es un hecho contemporáneo. Desde la Edad Media se establece el precio que se ha de pagar si se vierten aguas sucias procedentes de curtidos, tintes o agua de pescado. Igualmente se establece una cuota para quienes lavaren paños de lino o lana siendo diferente la cuantía si es en el río o en una fuente o en un pilón:

Otrossi, hordenamos e mandamos que los cortidores que echaren ... aguas suzias de sus cueros que paguen doze maravedis (Ávila, 18)

Que los pescadores nyn otras personas non derramen agua de pescado en las plaças nyn mercados nyn en las calles de Avyla (Ávila, 18).

Hordenamos e mandamos que las personas que tovieren cargo de bastecer nuestras pescaderias nyn otras personas algunas que non sean osados de verter las aguas de tales pescados en las plaças nyn calles publicas (Ávila, 18).

... mandaron echar el agua de los tintes por la calle de Barrientos, por quanto entienden que es mas syn daño de la villa (Piedrahíta, 22). 
Se castiga, tambien, que contaminen ríos o charcos con hierbas para matar pescados:

Hordenamos e mandamos que ... non sean osados en ningun tienpo de echar nin de mandar echar ninguna yerva nin yervas, de ninguna calidat que sean, en los tales rios, pesqueras o charcos e piedras para matar nin tomar peçes, barvos, truchas, anguillas ... (Ávila, 18).

Más tarde se prohíbe que se lave en los pilones, sobre todo lana negra, por temor a que sufran daño tanto los vecinos como el ganado que va a beber alli, bajo la pena de ser atado en una picota, de una a cuatro, el primer día de mercado porque la multa marcada antes resultaba ser escasa:

...muchas vezes se ha visto que se lava lana negra de caldera en los dichos pilones; e otras veces se a visto hechar servidores y otras cosas suzias en los dichos pilones, de lo qual redunda mucho daño e peligro a los vezinos desta villa, porque, de noche e de dia, andan a comer sus bestias e ganados en los dichos pilones e a bever en ellos. Y, muchas vezes, a acaescido que los dichos vezinos beven del agua de las pilas de los dichos pilones.» (Piedrahíta, 139).

Continuando con la preocupación que sentían las autoridades municipales de la Edad Media por el agua sucia -agua al fin y al cabo- encontramos otro texto de Ávila en el que se dispone que una vez empedradas las calles para evitar que haya lodos se mantengan limpias y que la gente se abstenga de arrojar basuras y otros deshechos por las ventanas:

... e agora por no se modar (sic) a linpiar las dichas calles empedradas ay en ellas muchos lodos, e de las casas se echan por los alvariares e las ventanas e por otras partes vasuras e aguas teñidas e çernadas e baçinadas e otras, por ende hordenaron que de aqui adelante ninguna ni algunas personas non sean osadas de echar ni echen en las dichas calles enpedradas vasura nin baçinadas nin orines nin aguas teñidas nin xabonaduras nin çernadas, so pena de ... (Ávila, 41).

Dámaso Alonso ${ }^{24}$ en un trabajo titulado «... si no le viera la cruz», en el que rastrea los orígenes de un epigrama atribuído a Góngora, dice que «las rinconadas, sobre todo en sitios de poca luz, han sido muy aprovechadas por los hom-

24 Alonso, D.: «...si no le viera la cruz» en Homenaje al Prof. Muñoz Cortés. Univ. de Murcia, 1977, 2 vols.; vol. I, págs. 27-35. 
bres para exonerarse de sus aguas, ya menores o ya mayores ...» por lo que los municipios con el fin de mantener las calles limpias mandan colocar una cruz, lo que despierta muchas protestas porque se le daba un uso irrespetuoso ya que no se conseguía el proposito inicial de evitar que los vecinos virtieran basuras:

Pusiéronle la kruz porke no le measen

Malizia kontra uno de ábito, ke no era de buen talle, sino chiko y feo. Solíanse poner kruzes en rrincones de patios i zaguanes porke no measen en ellos; mas ia está xustamente mandado ke no se pongan. i borrar las ke estaban pintadas en desonestos lugares (Gonzale Korreas: Vocabulario de refranes ...; apud D. Alonso).

En los documentos medievales también se reflejan otros problemas que hasta ahora podríamos pensar que eran sólo actuales. En Las Ordenanzas Medievales de Ávila y su tierra se establece castigar a los que pesquen en ríos y arroyos sin usar las redes u otras artes, que marcan los concejos quitándoles el pescado o poniéndole una multa:

Hordenamos e mandamos que ninguno ni algunos de Avila... non sean osados de pescar en los ríos e arroyos e charcos e piedras de la dicha çibdat e su tierra con nyngunas redes ni redejones nyn con otras parancas nyn con cestos ny nasas ni lençuelos ni camysones algunos, ssalvo con aquellas que fueren fechas por el marco que nos el dicho concejo tenemos fecho, que es éste que aqứ va señalado en esta hordenaça (Ávila, 18).

De la misma manera se prohíbe desecar charcas para pescar con el fin de proteger a los alevines bajo pena de una multa que dividirán en tres mitades y la última en dos cuartas partes, lo que demuestra una vez más que no revisaban ni corregían los escritos y, por ello, es frecuente encontrar la misma palabra escrita de distinta forma en el mismo folio o errores en sumas, etc,

...hordenan e mandan que ninguno sea osado de vaziar los dichos charcos nin matar nin tomar el dicho pescado, commo dicho es, so pena que, ..., caya en pena cada uno cada vez de mil maravedis, la miatad para la camara de sus altezas e la otra mitad para las obras publicas ... e la otra mitad (sic)...

En la línea de proteger el equilibrio ecológico se prohíbe en el Fuero Real que se cierren los ríos y se perjudique el pescado o el comercio: 
[VI] Ningún omne non sea osado de ençerrar los ríos mayores que entran a la mar por que salen los salmones, et los sollos, et otros pescados de mar, et porque andan las naues con las mercaduras de las unas tierras a las otras (F.Real, L IV, T.VI).

Agua helada, pero agua, es la nieve. En las Ordenanzas de Ávila se prohibe matar animales en invierno en este contradictorio y reiterativo. Texto

[se prohibe] matar e las liebres, en toda tierra de Avila en tienpo de nyeves, so la dicha pena, ssalvo con galgos, pero no en tienpo de las nyeves, eçepto con ballesta, pero no en tienpo de nyeves (Ávila, 18).

También se dispone dónde ha de beber el ganado y cuándo lo ha de hacer so pena de multas o castigos:

Ytem, que en quanto al bebedero de los ganados, que se entiende ençima de la Mata e debaxo del camino de Piedrahita hasta los prados de los Mimbrales, que pueden llegar a beber e abrebar sus ganados (Piedrahita, 49).

E que puedan bever las aguas de dia, como dicho es, syn pena alguna» (Ávila, 18).

E todos los otros ganados del monasterio de Cannas anden salvos e seguros por todas las partes de mis regnos e pascan las yervas e bevan las aguas assi como los mios mismos (Rioja, 384)

Et encara fuessen et sian en paciffica possession de paxentar sus ganados ... et de cabanyar en los ditos terminos de dia et de nueyt et de abrevar en los abrevaderos de los ditos terminos de Aliaga (Mirav., 11).

Podríamos continuar explicando cómo se repartían las aguas, cómo se les daba paso de una parte a otra, cómo se castigaba el robo del agua o los daños que causaba si se le desviaba o qué aguas se destinaban al regadío, pero creemos que es el momento de concluir.

Si comparamos ahora estos documentos notariales medievales, articulados sobre la base de lexías complejas, en los que se pueden detectar los rasgos lingüísticos propios de los escribanos aunque la estructura sea idéntica, con los artículos que aparecen en la prensa, no hace falta acudir a textos legales, veremos que los problemas y los contenidos son muy semejantes. La disputa por un trasvase o por obtener agua para un regadío; épocas de gran escasez que alteman 
con grandes riadas, no sólo en el sur sino también en el norte. La mano del hombre está presente siempre.

Se legisla para proteger el medio ambiente de un deterioro galopante, pero -ya hemos visto- que se hace desde tiempos inmemoriales. A la vez, se desvían los cauces de los ríos, se construye en el cauce de las ramblas, los vertederos amenazan a la población y el mar, arden los bosques o cada día hay más especies animales en extinción. Eso sí, los textos legales estarán redactados con formulas que nos recuerden las medievales y ésto indica una vez más que la lengua jurídica viene a cambiar por decreto, no se desgasta como la lengua común por el uso. 